Portland State University

PDXScholar

$1-27-2017$

\title{
Current Efforts to Make Bike Share More Equitable: A Survey of System Owners and Operators
}

Steven Howland

Portland State University

Follow this and additional works at: https://pdxscholar.library.pdx.edu/trec_seminar

Part of the Social Policy Commons, Transportation Commons, and the Transportation Engineering Commons

Let us know how access to this document benefits you.

\section{Recommended Citation}

Howland, Steven, "Current Efforts to Make Bike Share More Equitable: A Survey of System Owners and Operators" (2017). TREC Friday Seminar Series. 107.

https://pdxscholar.library.pdx.edu/trec_seminar/107

This Book is brought to you for free and open access. It has been accepted for inclusion in TREC Friday Seminar Series by an authorized administrator of PDXScholar. Please contact us if we can make this document more accessible: pdxscholar@pdx.edu. 


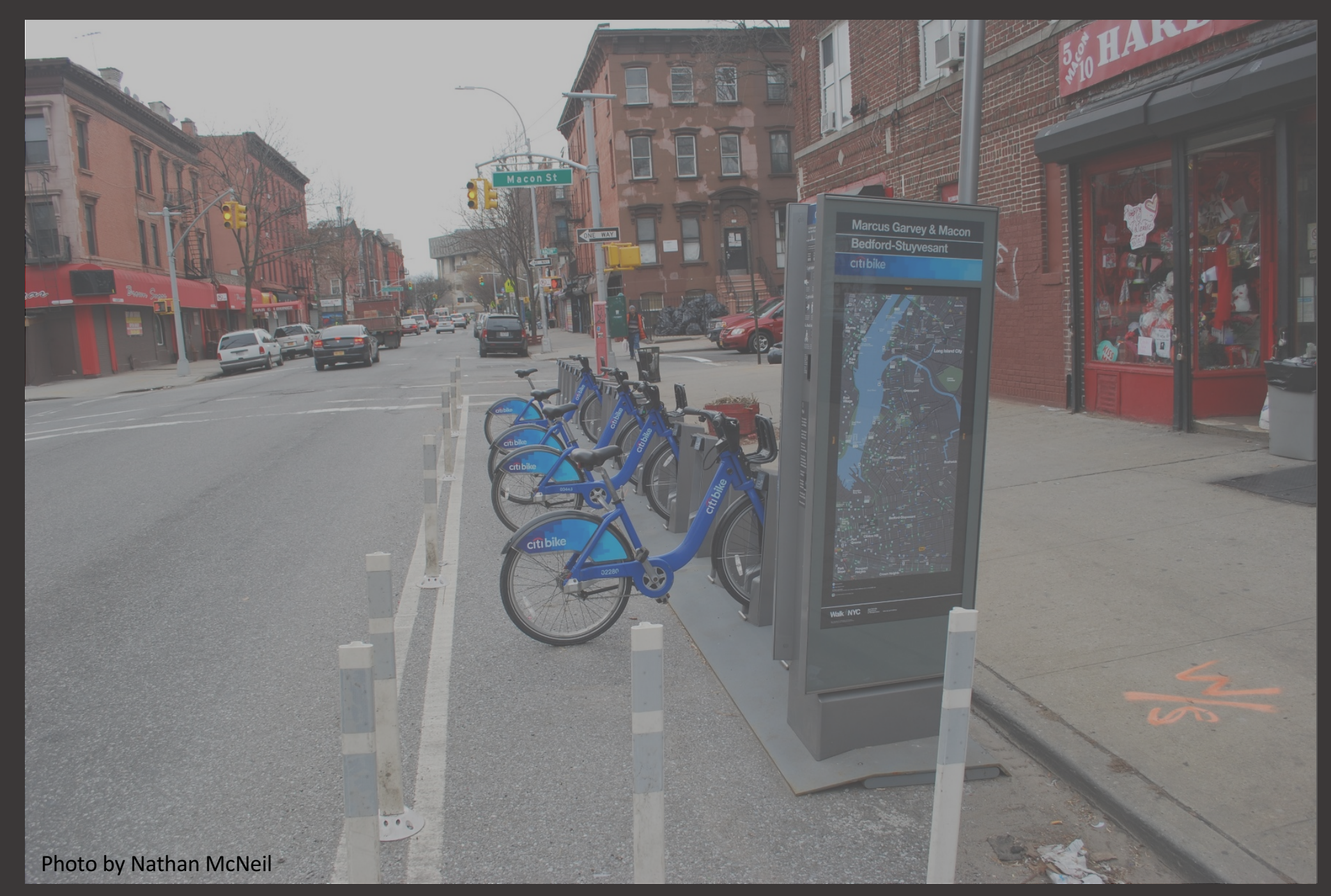

\section{Current Efforts to Make Bike Share More Equitable}

\section{A Survey of System Owners and Operators}

Steven Howland

Nathan McNeil

Joseph Broach, PhD

Kenneth Rankins

John MacArthur, PhD

Jennifer Dill, PhD

Portland State University

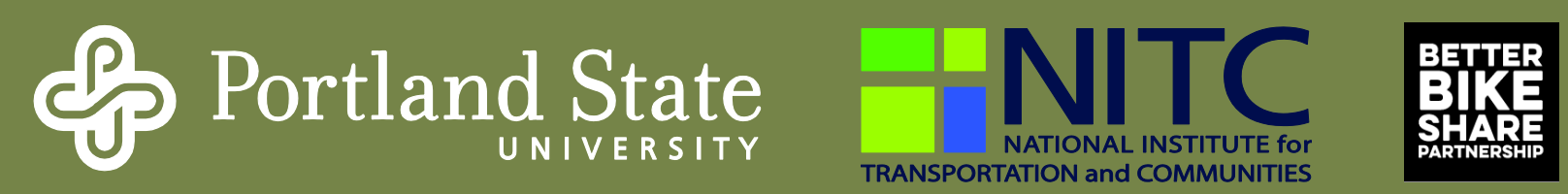




\section{Equity}

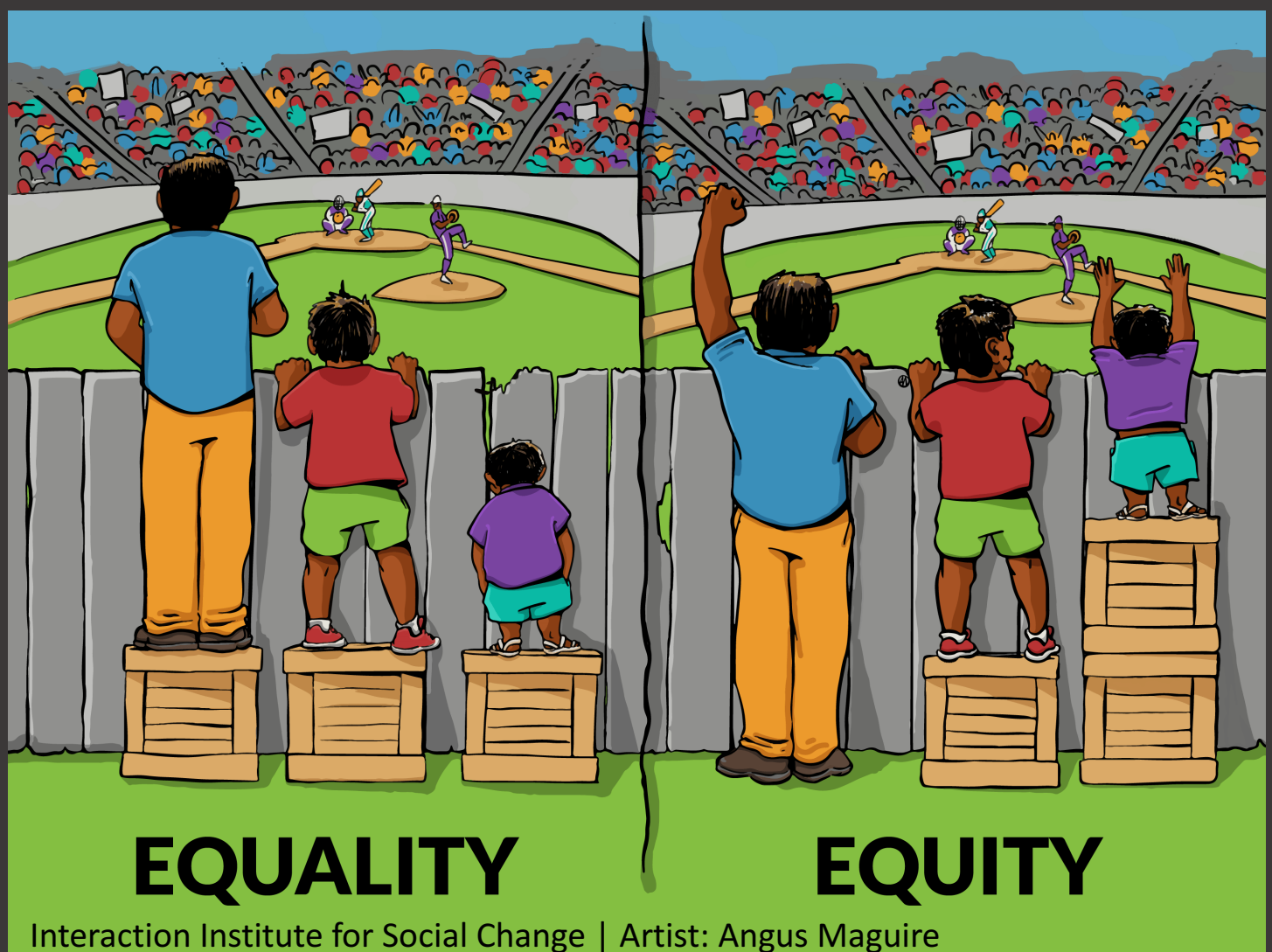

\section{What is it?}

- Recognizing that some groups have a disadvantage compared to others

- Efforts to correct disadvantage need to take into account level of disadvantage 


\section{Equity}

\section{How did we apply it?}

\section{EQUALITY VERSUS EQUITY}

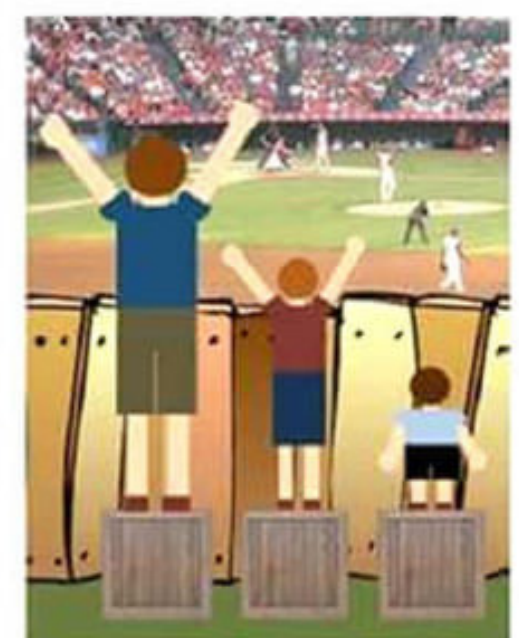

In the first image, it is

assumed that everyone

will benefit from the same

supports. They are

being treated equally.

Culturalorganizing.org

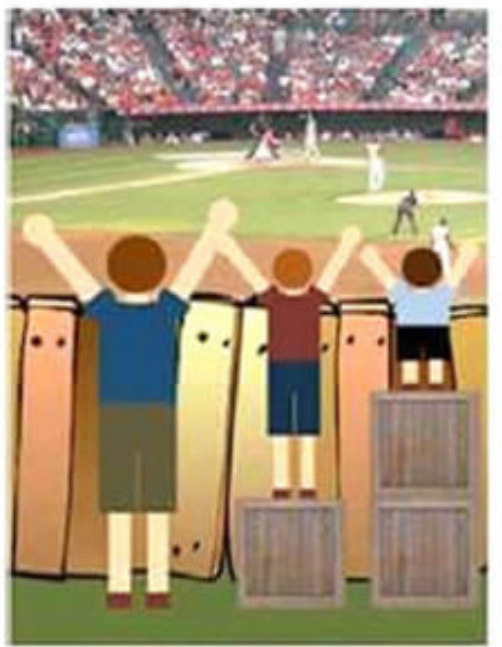

In the second image, individuals are given different supports to make it possible for them to have equal access to the game. They are being treated equitably.

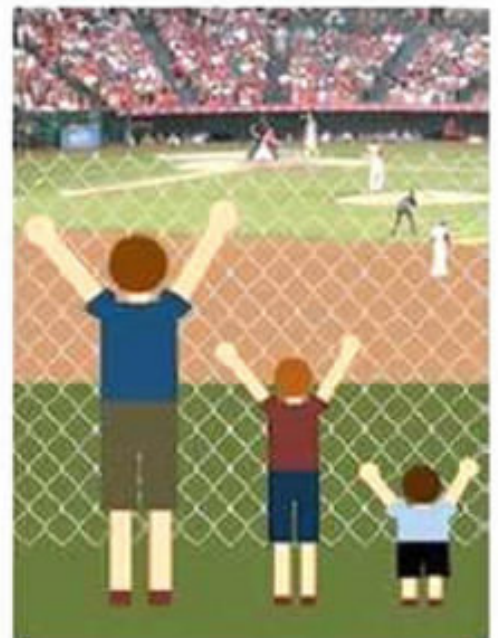

In the third image, all three can see the game without an supports or accommodations because the cause of the inequity was addressed. The systemic barrier has been removed.

- League of American Bicyclists:

- "the guarantee of fair treatment, access, opportunity, and advancement for all, while at the same time striving to identify and eliminate barriers that have prevented the full participation of some group"

- Advocacy Advance:

- "recognizing and reacting to the underrepresentation of youth, women, and people of color in advocacy efforts and local transportation decisions."

- Additional:

- Low-income

- Older Adults

- Recognize ramifications of past and ongoing inequity

- Equity in terms of not just focusing on raising disadvantaged groups above barriers, but removing barriers all together 
Identify Bike Share Organizations

- Pedestrian and Bicycling Information Center

- Web searches

- National Association of City Transportation Officials

- Developed a list of 75 bike share systems and persons for contact

- Excluded systems with fewer than 40 bikes

- Emailed contact persons March 2016

- 3 reminders sent

\section{Survey}

- Structure

- Typology of systems (\# bikes, owner/operator, public/private, system operational

- Equity statement (yes/no)

- If yes, provide the statement

- Metrics to measure

- Role of Equity in:

- Station siting

- Fee structure and payment systems

- System operations

- Promotion, outreach, and marketing

- Data Collection

- Perceived barriers for users

- Barriers for the organization 


\section{ANOVA}

- Comparing Role of Equity with size and type of system

\section{Content Analysis}

- Equity statements and open ended responses

- Over 200 codes were identified across all pieces of the survey

- Combined codes were used for final analysis

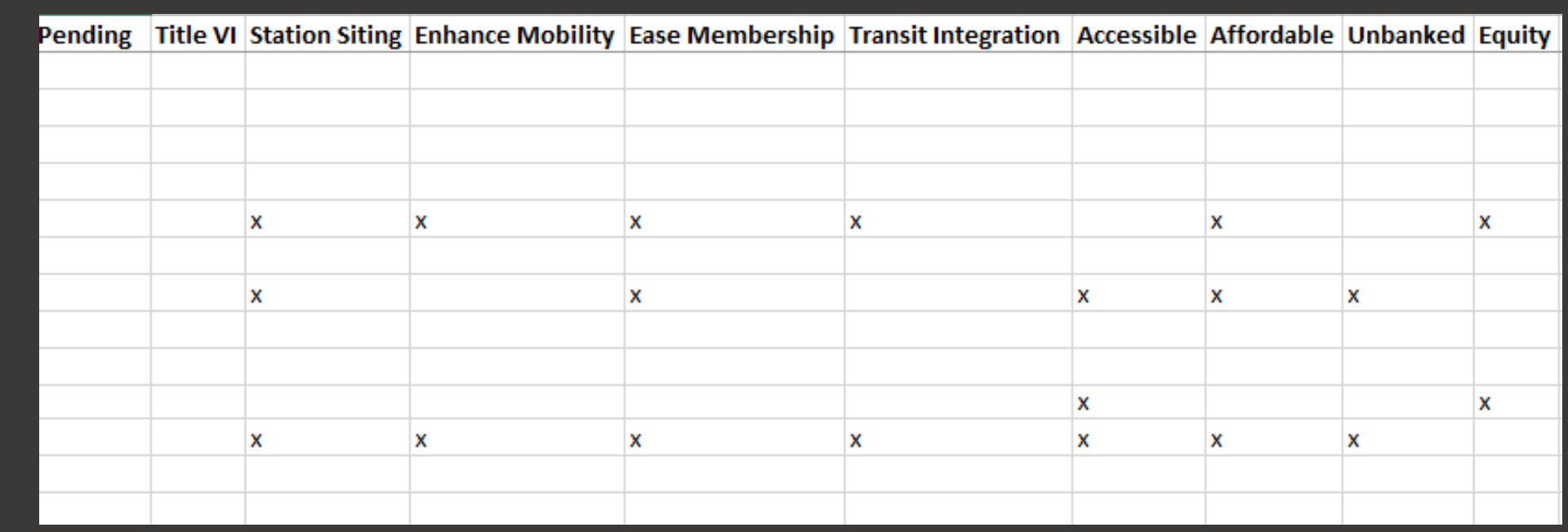




\section{Respondents}

\section{Responding Organization and Bike Share System} Characteristics $(n=55)$

Responding Organization Role in Bike Share System

Percent of Responding

Organizations

Owner

$33 \%$

Operator

$24 \%$

Owner and Operator

$29 \%$

Partner - Not owner or operator

$14 \%$

\section{Responding Organization Type}

\begin{tabular}{|l|c|}
\hline \multicolumn{2}{|c|}{ Responding Organization Type } \\
\hline Government & $\begin{array}{c}\text { Percent of Responding } \\
\text { Organizations }\end{array}$ \\
\hline Non-profit organization & $44 \%$ \\
\hline Private Operator & $40 \%$ \\
\hline University & $11 \%$ \\
\hline Launch Status & $6 \%$ \\
\hline \multicolumn{1}{|c|}{ Operational } & \\
\hline Pre-launch & $82 \%$ \\
\hline
\end{tabular}

Number of Bikes in System

Percent of Responding

Organizations

Up to 100 bikes (small)

101 to 500 bikes (medium)

501 or more bikes (large)

$26 \%$

$51 \%$

$24 \%$

\section{U.S. Census Region}

\begin{tabular}{|l|c|}
\hline \multicolumn{2}{|c|}{ U.S. Census Region } \\
\hline Northeast & $\begin{array}{c}\text { Percent of Responding } \\
\text { Organizations }\end{array}$ \\
\hline South & $13 \%$ \\
\hline Midwest & $24 \%$ \\
\hline West & $29 \%$ \\
\hline
\end{tabular}




\section{Equity Statements}

systems stated they had an equity statement

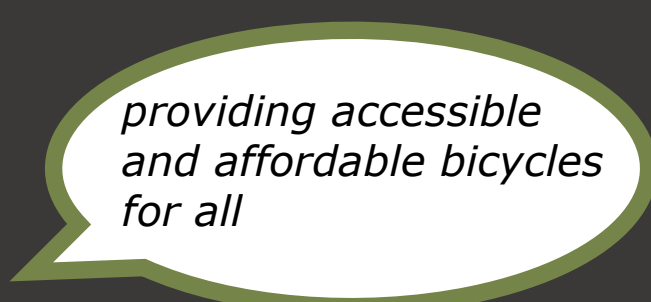

$\rightarrow$ More likely to be large systems

- More likely to be in more diverse cities (Median \%non-white +21 percentage points)

$\rightarrow \quad$ Tended to consider equity in more decisions

\section{Which systems have equity statements?}

and affordable bicycles
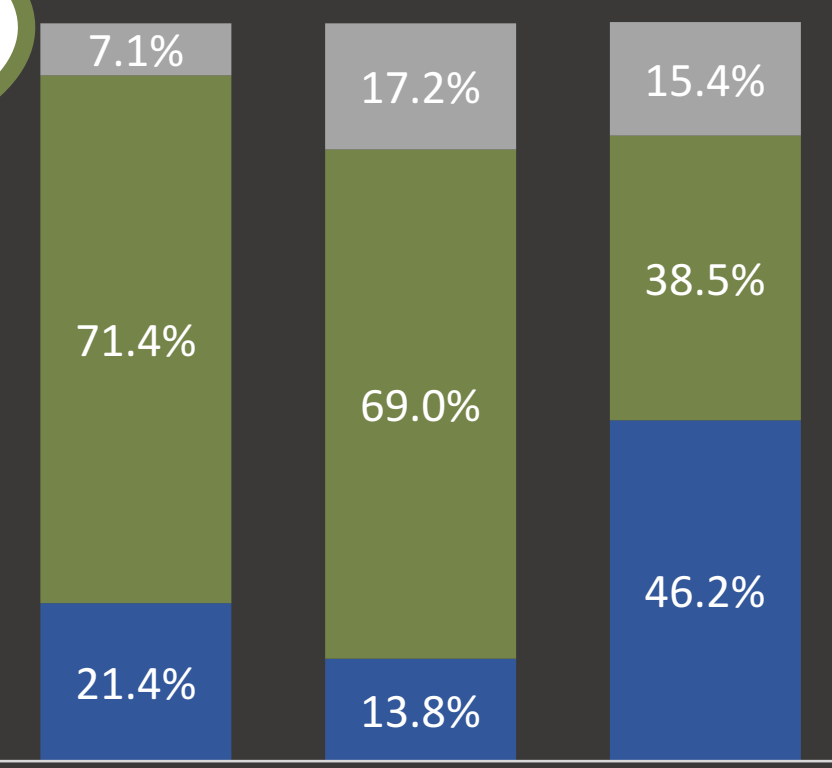

Only 3 systems provided what we considered extensive statements, incorporating...

Up to $100 \quad 101$ to $500 \quad 501$ or more All surveyed

bikes $(n=14)$ bikes $(n=29)$ bikes $(n=13)$

\section{systems} $(n=56)$

$\rightarrow \quad$ Who they were targeting

$\rightarrow$ How they were targeting them

$\rightarrow \quad$ Specific goals they hoped to achieve

equity was not a major consideration in the initial roll out of our bike-share system, it has become increasingly important as the system grows and additional stakeholders become
Establish a system that engages and serves users in minority, low income, and limited transit option communities and help improve access to jobs, recreation and healthy 


\section{Equity Statements}

\section{NO Equity Statement}

33 systems stated they did not have an equity statements

$\rightarrow$ Typically smaller systems

$\rightarrow \quad$ Cities tended to be less racially diverse (Median \%non-white -21 percentage points)

$\rightarrow$ Many stated they had equity statements in development

Lack of an equity statement may be due in part due to less political pressure and fewer resources in these smaller, less diverse cities.

\section{"Other" Responses}

\section{Equity Statement Presence and Incorporation of Equity in} Bike Share

Without Equity Statement

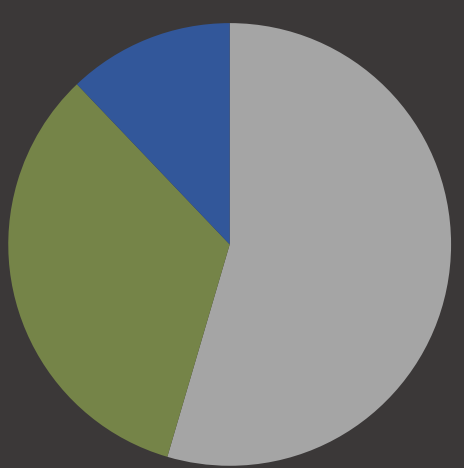

Note: Number of key areas where equity had "considerable" or "primary" role. Those responding "Other" to whether they had an equity statement were excluded.

7 systems responded "other" to whether they had an equity statement. Almost all had statement or policy under development 


\section{Equity in Bike Share Elements}

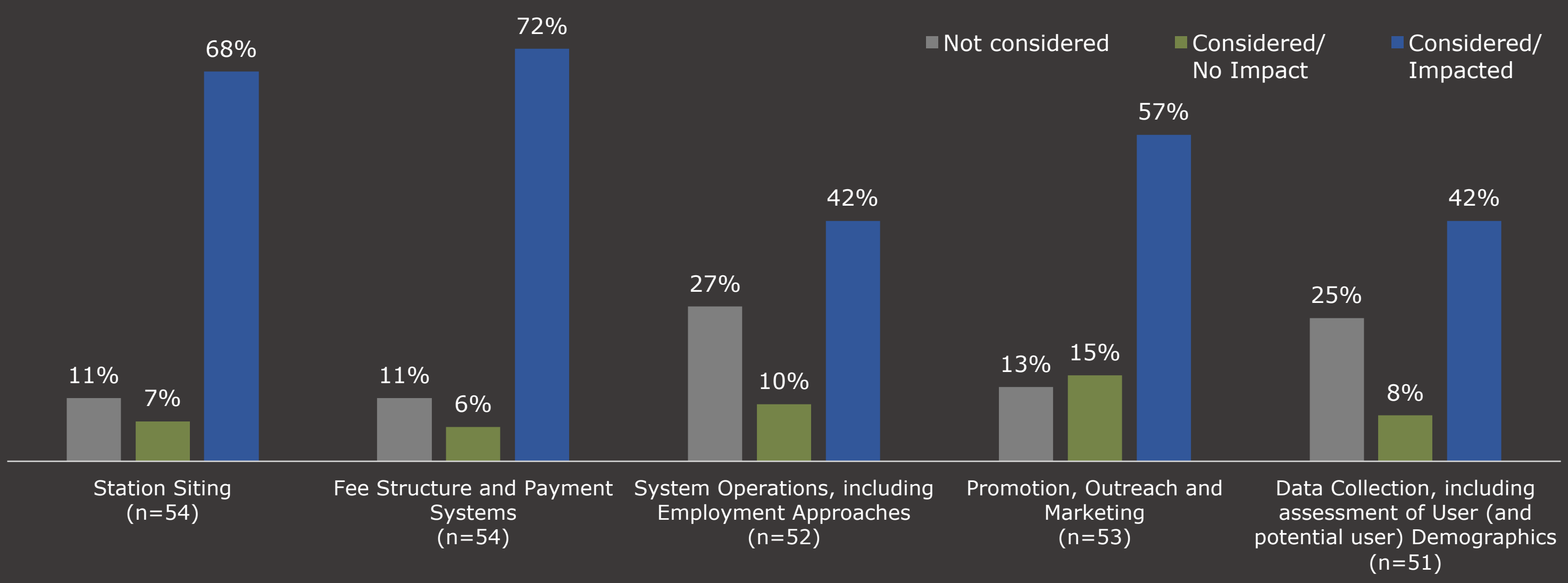

Note: Percentages do not total $100 \%$ due to "Don't Know/NA" responses. Possible survey responses were: Not considered; considered, no impact;

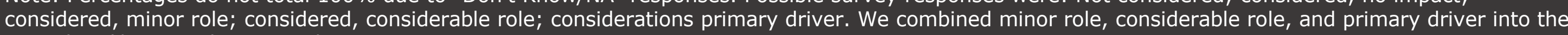
Considered/impacted category here. 


\section{Equity in Station Siting}

Promote transit connectivity

Connection to destinations

$\rightarrow$ Jobs

$\rightarrow$ Commercial/retail districts

$\rightarrow$ Recreation

Station placement at public housing complexes

Large coverage areas

Walkable distances between stations

Very few had quotas for number or percentage of stations in low-income and minority neighborhoods.

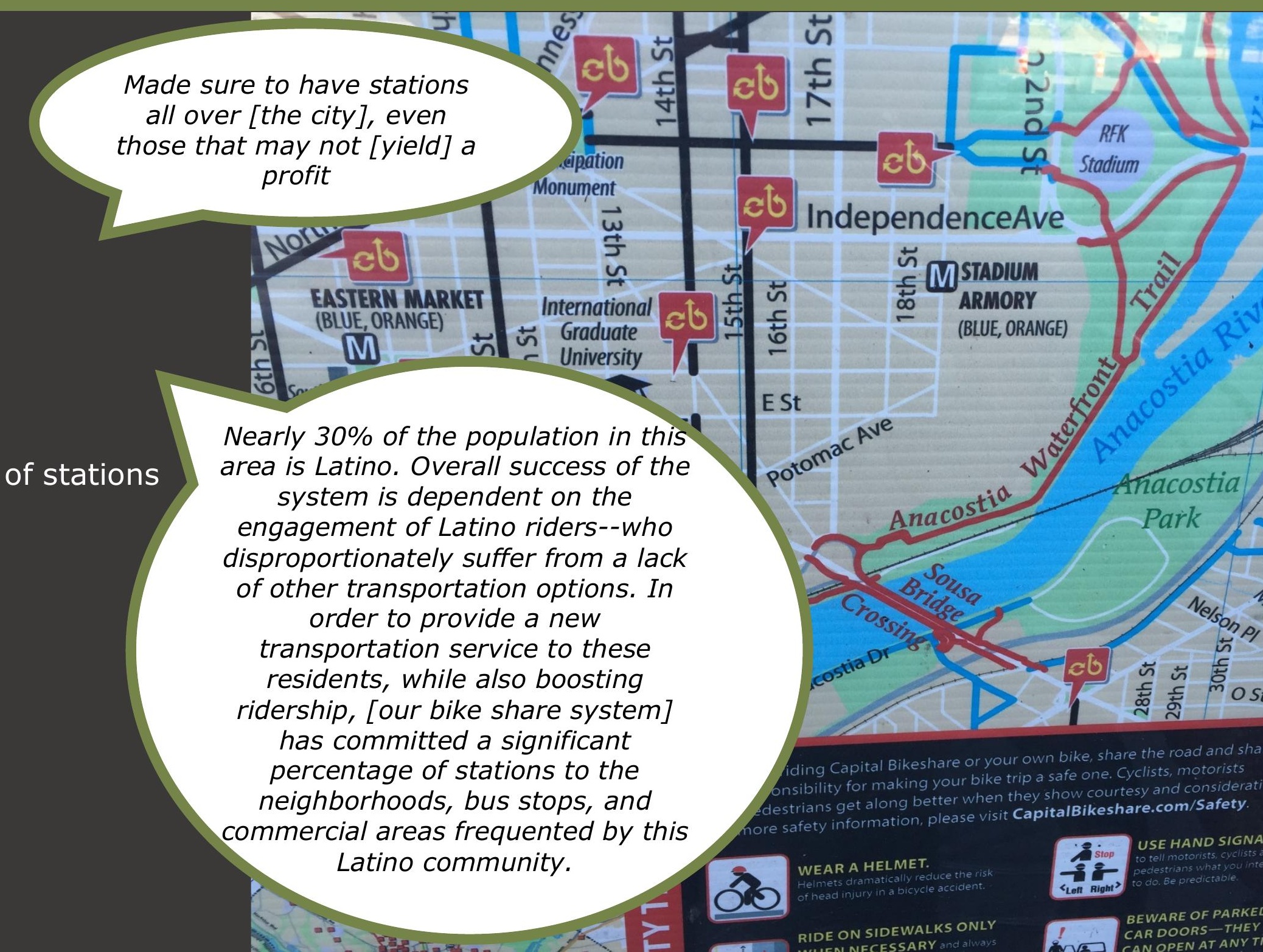

As we site stations, we are examining locations that are proximate to transit stops, highdensity housing, which is

typically low-income in this area, jobs, and key destinations. While not targeting specific populations, we also conducted an online survey where participants were asked to pick their top 5 station locations.

Nearly $30 \%$ of the population in this ea is Latino. Overall success of the disproportionately suffer from a lack other transportation options. In mmercial areas frequented by this 


\section{Equity in Fee Structure/Payments}

\section{Cost}

Reevaluated pricing and dropped prices accordingly

Reduced or eliminated bank holds

Added membership options

$\Rightarrow$ Employer discounts

$\rightarrow$ Monthly and weekly passes

$\rightarrow$ Pay-per-ride structures

$\rightarrow$ Changed yearly membership to be able to be paid monthly

Simplify fee structure to make it easier to understand

Use of contract bid process to solicit "innovative fee structures"

\section{Discounts}

14 systems said they had discounted or free memberships

One system obtained a grant to give their target equity population a zero cost program

Qualifications:

$\rightarrow$ Receiving public assistance

$\rightarrow \quad$ Income thresholds

Discounts ranged considerably

Tied to low income populations and typically not race/ethnicity specific.

\section{Payment Systems}

13 systems said they were trying to meet the needs of unbanked populations

Cash payment options

$\Rightarrow$ Use of commercial establishments to facilitate transactions

$\rightarrow \quad$ One was using its library system

Allowing for use of pre-paid debit/credit cards

One also looking at ways to incorporate homeless populations

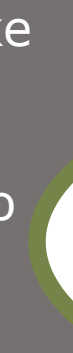

We took information from our focus group, conducted in advance of launch, with low income [populations] into account and priced with this in mind.
Adding

Adding membership and payment options: monthly installments for annual members, smaller "hold" charges on credit/debit cards, non-web-based payment interfaces, and exploring how to accept cash payment and/or combined bike share/transit passes. 


\section{Hiring Processes}

Typically looked at hiring locally and paying living wage

Five systems said they partnered with local workforce development organizations or public housing to find potential hires

Some hired persons matching the demographic they were trying to reach with their equity programs as advocacy staff

\section{Operations}

Some stated their ability to incorporate equity in this element was restricted by how their operations were organized 


\section{Equity in Promotion/Marketing / Outreach}

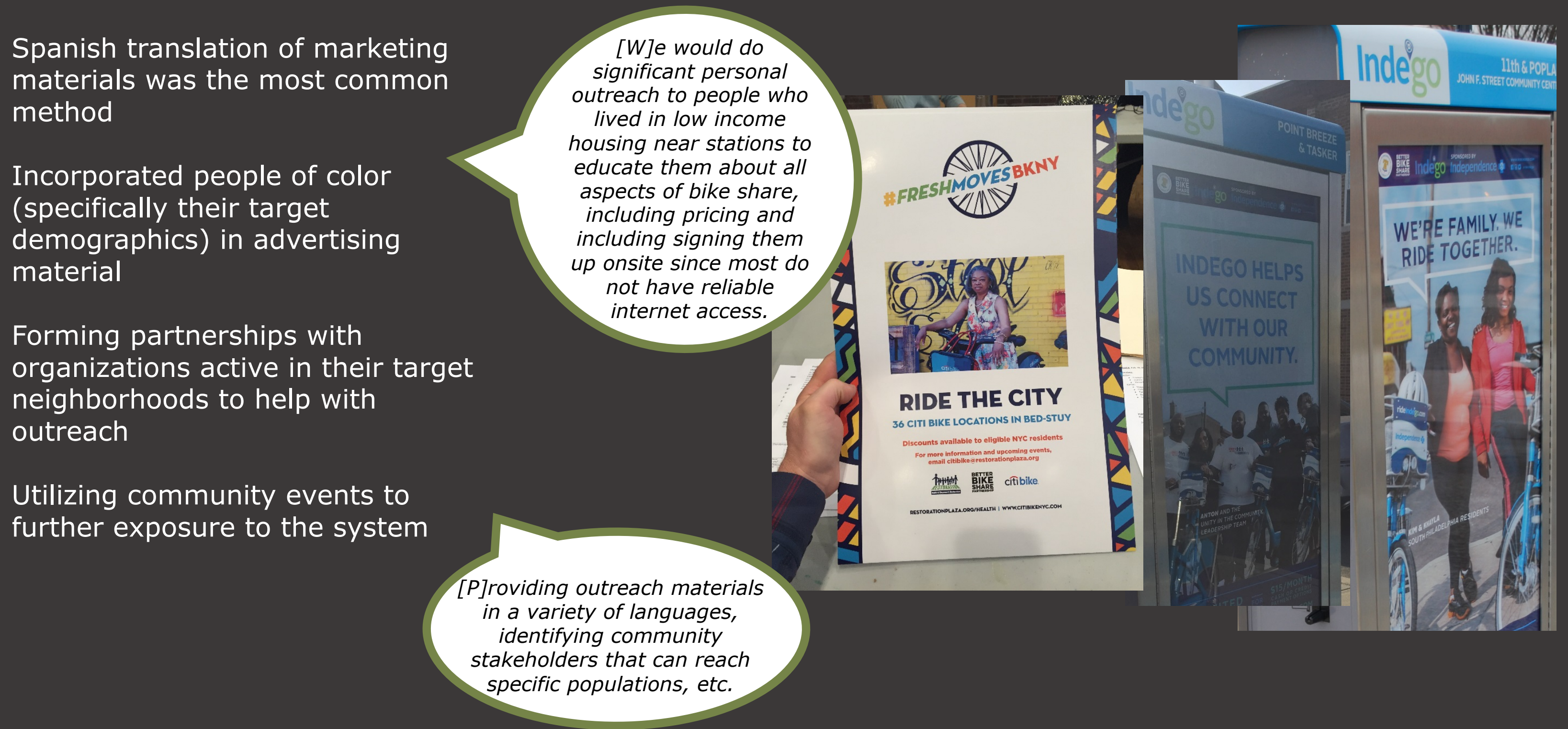




\section{Equity in Equity Metrics/Data Collection}

Only a few specified equity metrics tied to specific equity goals

$\rightarrow$ Quota percentage of stations near targeted equity populations

$\rightarrow$ Track usage by low-income pass users to develop better understanding of their patterns: goal to reach specific number of trips per user

$\rightarrow$ Monitor overages: goal to limit overage to certain $\$ /$ month

$\rightarrow$ Set goal of \% of women members

$\rightarrow$ Set goal of \% of low-income users, w/ associated gender goal among lowincome users

Data Collection

$\rightarrow$ Lack of clarity in which members they wanted to survey in most cases

$\rightarrow 5$ systems aimed to use the data collected to measure progress toward equity goals 
Over $80 \%$ of respondents ( 44 systems) shared what they thought were key barriers to participation for targeted equity populations in their cities. Generally, the barriers fell into the categories of pricing and payment systems; various aspects of access; perceptions of bike share and bicycling in general; and awareness, education, and understanding of how the system works.

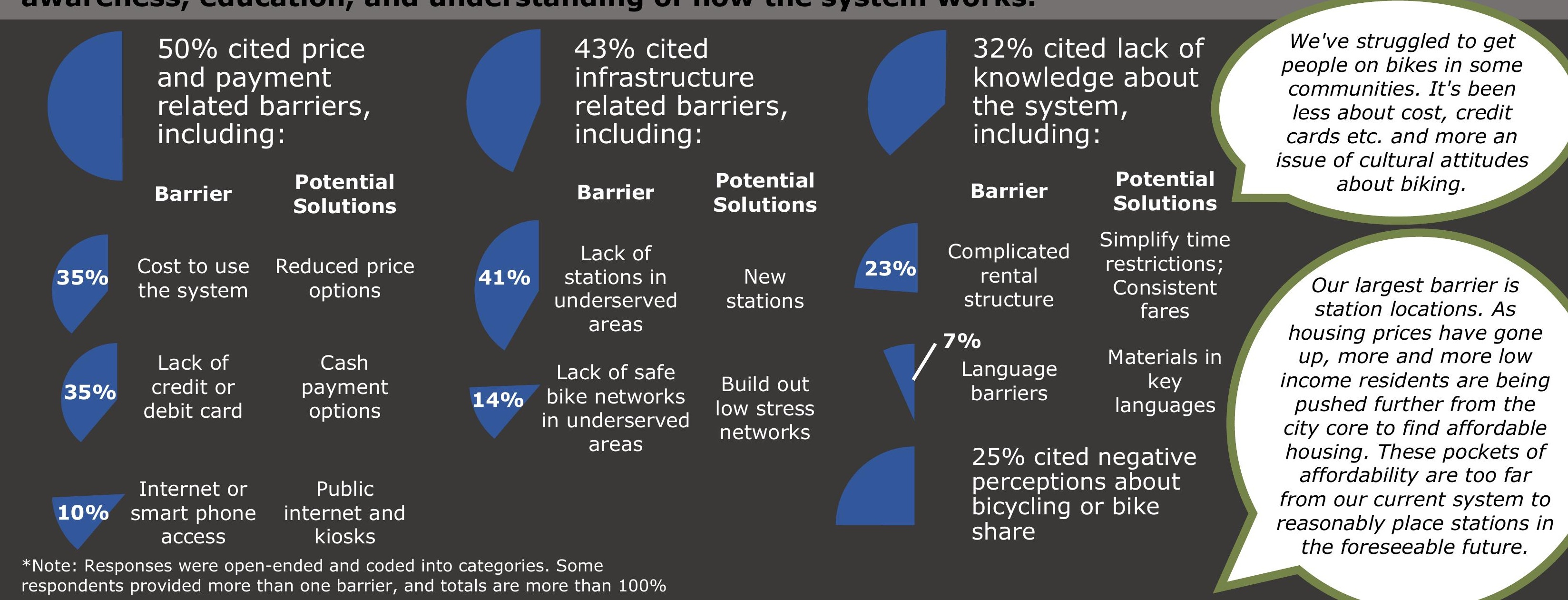


Equity is something most bike share systems are thinking about if not incorporating

Equity statements are important to incorporating equity throughout the system.

Equity statements should be specific

- Who are you wanting to target?

- How are you planning to target them?

- How are you going to track your progress?

The biggest barriers cited by bike share organizations are being worked on through equity strategies

- $68 \%$ are incorporating it in station siting

- $72 \%$ are incorporating it in fee structure and pricing

- $57 \%$ are incorporating it in promotion, marketing, and outreach

Equity is a fairly new concept in most bike share organizations. As such, best practices on what works and what does not is yet to be known. 
Steven Howland

Email: showland@pdx.edu

Twitter: @showland886

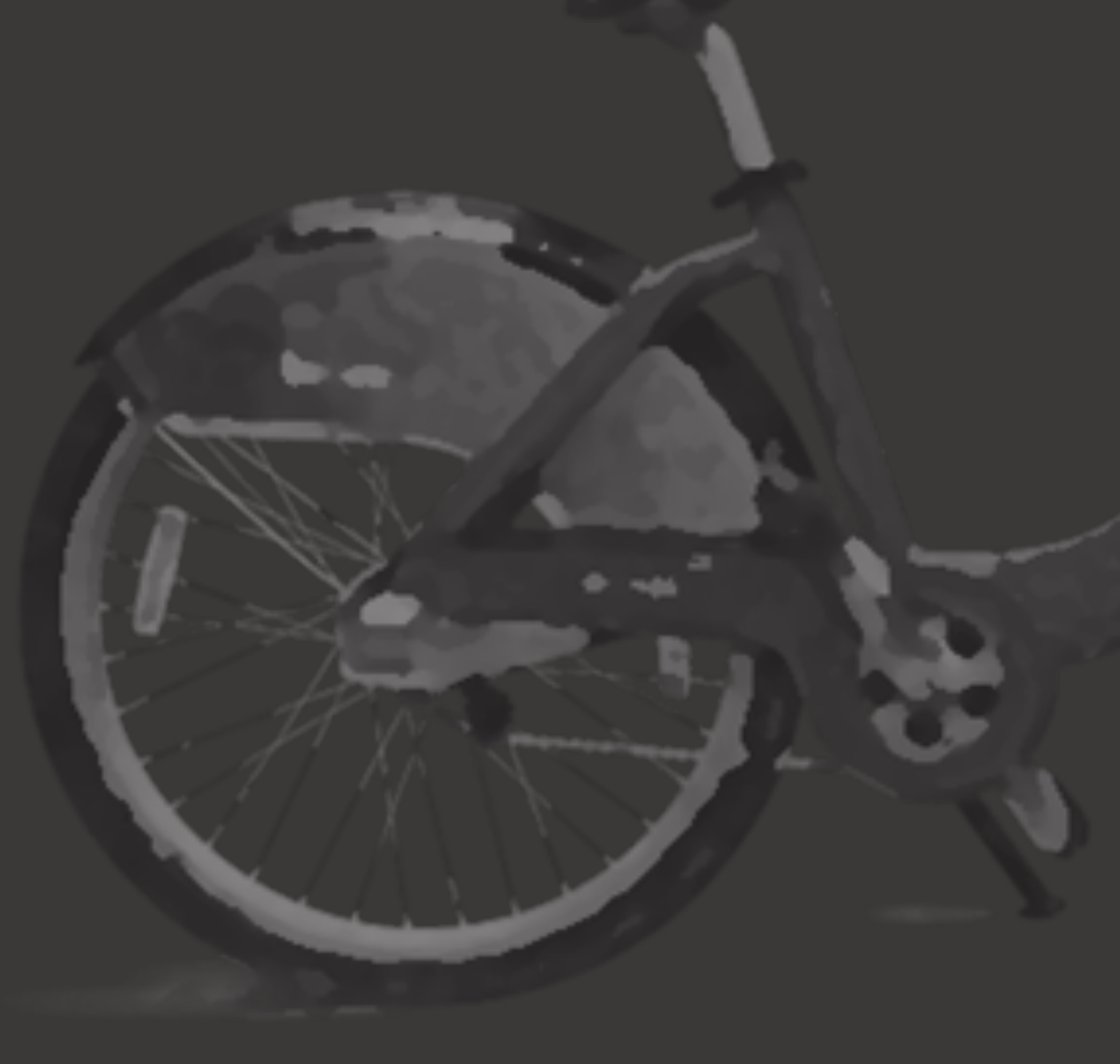

